\title{
Six Propositions of a Social Theory of Numeracy: Interpreting an Influential Theory of Literacy
}

Jeffrey Craig

University of Arizona, jeff.craig222@gmail.com

Lynette Guzmán

University of Arizona, Idguzman@math.arizona.edu

Follow this and additional works at: https://digitalcommons.usf.edu/numeracy

Part of the Curriculum and Social Inquiry Commons, Science and Mathematics Education Commons, and the Social and Philosophical Foundations of Education Commons

\section{Recommended Citation}

Craig, Jeffrey, and Lynette Guzmán. "Six Propositions of a Social Theory of Numeracy: Interpreting an Influential Theory of Literacy." Numeracy 11, Iss. 2 (2018): Article 2. DOI: https://doi.org/10.5038/

1936-4660.11.2.2 


\title{
Six Propositions of a Social Theory of Numeracy: Interpreting an Influential Theory of Literacy
}

\author{
Abstract \\ We share our experiences comprehending social theory as it applies to numeracy scholarship. We build \\ on existing arguments that social theory-explicitly acknowledging the presence and influence of \\ histories, power, and purposes-offers something important to scholars who study and discuss \\ numeracy. In this article, we translate the six propositions of one particular social theory of literacy into \\ propositions about numeracy, then we explore the meaning of each proposition, its connections to \\ existing scholarship, and its implications. This article emerges from two literature reviews: one on social \\ theories (especially their application to and development in literacy) and one on numeracy. We bring these \\ two reviews together through the decisions and connections we make during this translation. We hope \\ this account of our experiences can help other numeracy scholars as they approach, adapt, and apply \\ theory.
}

\section{Keywords}

numeracy, social theory, quantitative literacy, situated numeracy, social practices, literacy, numeracy practices, quantification, mathematics education

\section{Creative Commons License}

\section{(c) (i) (8)}

This work is licensed under a Creative Commons Attribution-Noncommercial 4.0 License

\section{Cover Page Footnote}

Jeffrey Craig, PhD, has a background is in mathematics education, specializing in numeracy. His research interests include: transdisciplinary education, education for wicked problems, and numeracy education. Lynette Guzmán, PhD, is a Visiting Assistant Professor at the University of Arizona. Her scholarship centers on mitigating inequities in education for historically marginalized students, with attention to identity and power. She works with prospective and practicing K-8 teachers to transform their classrooms with equity-oriented and humanizing practices that value young people. 


\section{Introduction}

About fifteen years ago, there was a sense of consensus regarding the relative urgency of improving numeracy ${ }^{1}$ versus defining it, as Bass $(2003,247)$ stated:

I agree with the views expressed that it is neither urgent, nor even necessarily productive, to attempt to achieve a precise consensus definition of [numeracy].

Scholars in the newly forming field of numeracy education were working diligently at the time, mostly within postsecondary education, to merely establish numeracy as something worth education's attention (the name of the volume in which Bass was writing was even titled Why Numeracy Matters). Now, Karaali, Villafane Hernandez, and Taylor $(2016,1)$ claimed, "scholarship in the interdisciplinary world of [numeracy] is thriving" and the discourse regarding numeracy has shifted, wherein it is now a challenge to find people who disagree that numeracy matters. It is also difficult to find people who believe numeracy is improving, despite its apparent importance and scholars' prolonged attention. Fifteen years ago it was sensible to prioritize the acknowledgement of numeracy as more important than theory.

We believe that it is appropriate to revisit the roles and importance of actively theorizing numeracy and its education. Numeracy, as most of its scholars have spoken of it, has by-and-large not been accomplished, nor even improved. Why not? One commonly assumed explanation is weak, or misdirected, mathematics education - a mathematics education that does not value nor understand the benefits of numeracy, suggesting a need for further educational reform (Craig 2017). Another explanation is the plurality of the goals of numeracy scholars: some want people to know basic, abstract mathematics, such as percentages and arithmetic; some want people to appreciate the power of mathematics and statistics; some want people to develop a habit of mind to apply their quantitative abilities to the world around them. This explanation suggests a need for consensus-building and resulting unification of numeracy efforts. A third possibility is that numeracy scholars, in their zeal to sell the importance of numeracy, overpromised what it could contribute, and therefore, scholars' attempts to meet those expectations were doomed from the outset (Craig 2017). This explanation suggests a need for more investigation of the potential and limits of numeracy. We are not sure to what extent any or all of those potential explanations are accurate, but we contend that numeracy scholars would collectively be divided among those explanations. We do

\footnotetext{
${ }^{1}$ Although scholars have used many terms to label this content-numeracy, quantitative literacy, quantitative reasoning, and mathematical literacy — we chose to use 'numeracy' throughout the rest of this piece. We do so to recognize that "the vast majority of proponents of quantitative literacy consider numeracy, quantitative literacy, and quantitative reasoning to be synonymous at least in some contexts" (Vacher 2014, 1).
} 
believe that theorizing is integral to clarifying our differences, and believe that numeracy largely remains, as Coben stated in 2006 (103) in an "under-theorized state."

Take Erickson's (2016) article "Rethinking the Numerate Citizen: Quantitative Literacy and the Citizen," for example. His paper disaggregated a broadly-defined numeracy by contemplating the power of numeracy specifically to resolve public problems. The resulting discussion between Hamman (2017) and Erickson (2017) is exemplary in its contributions to theorizing about numeracy. Hamman $(2017,1$, emphasis in original) argued that numeracy education attempts "to give students the tools and confidence to function in quantitative situations without actually doing the math themselves," whereas Erickson (2017) argued that the quantitative situations arising in public problems are not clarified by numeracy-that not being the person who did the math in these contexts necessarily shifted concern from epistemic independence to epistemic dependence. Regardless of the tools and confidence a person might have-their numeracy - trust is now the paramount concern.

To what extent are Hamman and Erickson in agreement? To what extent are their definitions of numeracy disjointed? Is Erickson's work, as he expects, really controversial to numeracy scholars? Or is it an example of our maturation as a field? We are not sure. But, their exchange illustrates what active theoretical discussion offers to our community. In this article, we explore a specific social theory of numeracy by translating Barton and Hamilton's (2000) social theory of literacy. These authors proposed six propositions scaffolding their theory, which Oughton $(2010,14)$ suggested "may be applied to numeracy." Although we found her work after we had completed several drafts of this work, we agree with Oughton's assessment. What we produce here, then, is a follow-through on her suggestion related to Barton and Hamilton's (2000) theory. Specifically, we detail how each of the six propositions in their social theory of literacy relates to numeracy scholarship by interpreting each proposition and synthesizing relevant numeracy work to clarify the implications for future work.

With serendipitous timing, Oughton (2018) has recently reintroduced social practice theory as it relates to numeracy. In her work, she skillfully demonstrated the potency of using a social practice theory to understand aspects of numeracy. Much of this potency derives from how social theories frame what is involved in numeracy. Oughton used social practice theory to revisit dominant discourses about numeracy made in policy documents. She considered the content on which policy documents typically focus and found themes of economics and mathematical remediation. These content foci likely belie a deficit discourse of numeracy, marked by a belief that "large proportions of adults struggle with the most basic skills" (OECD 2013, 8, as cited in Oughton 2018, 4) and a belief that a lack of these skills causes social and personal problems. 
Oughton (2018) also identified how the conclusion these policy documents made about the relationship between large-scale testing results and the everyday decision-making of those test-takers can be substantially challenged. One way is by questioning the authenticity of test questions relative to the everyday life moments they attempt to mimic, and another way is by examining the fidelity with which complex decision-making can be reduced to written, self-contained test prompts. Ultimately, she proposed that social practice theories of numeracy can help scholars to reconsider dominant discourses about adult numeracy. Oughton $(2018,14)$ wanted "to show how a social practice model offers a critical lens through which dominant discourses can be questioned and challenged, and alternative approaches sought." In this work, she skillfully applied a social practice theory of numeracy.

In contrast to her approach in that article, we begin with a specific social theory (of literacy) and discuss its meanings in terms of numeracy, and implications for numeracy scholarship. We do not take credit for considering social theories of numeracy, nor for any part of the development of the original social theory applied to literacy. Instead, our work was essentially the connection of two separate literature reviews: one on social theories (especially their application to and development in literacy) and one on numeracy. We brought these two reviews together through the decisions we made within our translation of Barton and Hamilton's theory.

Baker, Street, and Tomlin (2005) argued that social practice theories of numeracy expose the existence of four dimensions to numeracy: content, context, values and beliefs, and social and institutional relations. Our contributions in this article are (1) following through on the suggestion that Barton and Hamilton's social theory of literacy can be applied to numeracy (Papen 2005; Oughton 2010); (2) outlining the potential for analogizing texts in literacy with quantification in numeracy; (3) explicitly considering history and power dimensions to numeracy, in addition to the four above; and (4) continuing to connect scholarly work around numeracy together from a social perspective.

Further, this article emerged out of a three-year numeracy curriculum development and research program at Michigan State University, a large Midwestern University in the United States. The program involved two new courses in numeracy that were developed, piloted, and scaled-up. One way in which that program culminated was in a thesis (Craig 2017) with three primary conclusions: (1) that the promises made by numeracy scholars about the consequences of innumeracy and benefits of numeracy may be overstated; (2) that the primary goal of the two courses - making students into quantitative reasonerswas made partially irrelevant after witnessing the ease with which students quantitatively reasoned about their course projects; and (3) that an alternative approach to curriculum-based transdisciplinary thought has potential. Each of those conclusions partially involved the application of a social theory of numeracy 
described in this article. As a result, we attempt here to share the thinking that went into understanding Barton and Hamilton's (2000) social theory of literacy, and translating it in order to apply it to work in numeracy. Although others have applied social theories to numeracy, in this article we share our experiences making sense of one such theory.

\section{The Social Turn}

Of course, the idea of applying social theory is neither new to numeracy scholarship nor to mathematics education scholarship. In our assessment, however, it remains fairly underused in numeracy, so we share our experiences with applying the theory by detailing how we think about its implications for thinking about numeracy. Before focusing on our numeracy translation of Barton and Hamilton's (2000) social theory of literacy, we want to briefly describe social theories and their contributions to social science and education. Specifically, we focus on what some scholars have named the social turn in education research (e.g., Lave 1988; Gee 1992, 2010; Lerman 2000; Baker et al. 2003; Perry 2012; Gutiérrez 2013). Scholars use the "turn" metaphor to retroactively characterize a pattern of emerging theories and epistemologies within the wider landscape of research. A turn describes a set of scholarship that emerges across disciplines, discourses, and purposes, through its critiques of, and departures from, the more prominent theories, methods, and assumptions of that time. The social turn involved scholars from many domains challenging cognitive and behaviorist paradigms by including social activity as generative for "meaning, thinking, and reasoning" (Lerman 2000, 8).

The social turn, therefore, indicated an epistemological shift, primarily around the role of the individual in making meaning. The individual is partially decentered in social theories, and collective and localized meaning-making are centered alongside the individual, in ways which "go beyond the idea that social interactions provide a spark that generates or stimulates an individual's internal meaningmaking activity" (Lerman 2000, 8). Collective meaning-making involves the ways in which understanding (or literacy, or numeracy) develops among people and is shared-not entirely attributable to, nor belonging to, any single individual. Local meaning-making involves the ways in which understanding (or literacy, or numeracy) is situated within a particular time and space and, therefore, does not fully move (or transfer) as individuals disperse. Social theories imply that what people understood, said, and did, would have been different with different people involved, or at a different time, or in a different place. Social theories imply noninterchangeability of contextual features for meaning-making, and, in some way, resolve the longstanding issue of the concept of knowledge transfer.

Despite highlighting the ways that meaning-making is social, social theories do not discard the individual as an integral site of meaning-making. Arguably, the 
individual is even more in focus because each individual is indispensable when applying social theories. This is contrasted with psychological theories that attempt to universalize the individual. As Lerman (2000) suggested, considering the relationships between individuals, and among individuals and environments, is integral to developing social theories. Neither the individual nor communities "own" numeracy; it is neither wholly private nor wholly shared, but rather a concept that transgresses and straddles those boundaries. Knowing and knowledge are also considered from a social perspective in social theories. A conceptualization of knowledge as fixed, neutral, or decontextualized is scrutinized by illustrating the influences of history and power. What Street (1984) called the autonomous model of literacy, Perry $(2012,53)$ described as: "literacy is assumed to be a set of neutral, decontextualized skills that can be applied in any situation." The autonomous models frame literacy as something people are (i.e., literate), in contrast to social theories wherein literacy is something people $d o$.

Social theories of literacy question not only the possibility of abstracted, wholly private abilities, they also explicitly acknowledge the politics involved in defining and labelling people as literate. Sometimes considered separately as (socio-) cultural or (socio-) political turns, history and power affect not only how people make meaning, but when and whose meaning-making (or thinking, or learning) is recognized. As a result, social theorists actively disrupt how (or whether) ideas are defined. For instance, social theories of literacy explicitly attend and respond to how literacy has been used as a tool to mark people-specifically as a binary division between literate and illiterate-despite a lack of consensus on what literacy means.

These same issues arise in numeracy scholarship, especially the lack of consensus on what numeracy means and how it might be identified, despite actively measuring and labelling people based on their numeracy (Craig 2017). As the abilities to read and write text is important, so too are the abilities to do basic mathematics and statistics; however, we agree with Steen, who repeatedly emphasized that attending to the messiness of reality is what distinguishes numeracy from mathematics. For example, Steen $(2011,11)$ stated:

Mathematics is abstract and Platonic, offering absolute truths about relations among ideal objects. Numeracy is concrete and contextual, offering contingent solutions to problems about real situations. Whereas mathematics asks students to rise above context, quantitative literacy is anchored in the messy contexts of real life.

If numeracy scholarship is meant to deal with those subjects as they are applied to the social world, then we argue a sensible centerpiece of numeracy scholarship is people: the social. 


\section{A Social Theory of Numeracy}

In this article, we translate a social theory of literacy (Barton and Hamilton 2000). An immediate challenge to this work, as we briefly discussed in the introduction, comes from within numeracy scholarship. Steen $(2003,13)$ argued, "[numeracy] explorers have moved beyond debates about the definition of [numeracy], not because they reached consensus but because they recognize that development of [numeracy] programs is more important." There is merit to that position, as semantics might slow down action. We repeat, however, that we believe ongoing, critical, and explicit theorizing adds clarity to scholarship and, more importantly, opens up new possibilities by exposing our commonly held sensibilities to collective self-scrutiny.

Besides the potential benefits of conceptual and analytical work in developing numeracy programs, nearly fifteen years has passed. Changes to social, cultural, technological, and political contexts suggest to us that theorizing about numeracy is timely. Further, a dialogic relationship between developing programs and theorizing can exist productively; indeed, much of our theorizing has emerged alongside one author's dissertation that focused on a newly developed undergraduate numeracy program (Craig 2017). For this numeracy theorizing we turned to literacy, which generated a second challenge to the work: adapting a theory from another field. These concerns are not unfounded when "educational research and practice have been net importers of methods, theories, and discourses. Their histories have been ones of adopting (and sometimes, but certainly not always, adapting) interpretive frames from other disciplines, often with dubious results" (Davis 2008, 50). We attempt to circumvent these concerns here by restating our purpose as productive, not definitive; we want to open up conversations, not end them. We are making propositions, not conclusions.

We chose to pursue a social theory of numeracy in part because of how literacy scholars used social theorizing to account for a changing world. In their influential Case for Quantitative Literacy, Steen and colleagues (2001) proposed that numeracy was emerging as an important habit of mind for living during the twentyfirst century. They, and other numeracy scholars, attributed its emergence predominantly to technological changes; they argued that we now live in "[a] world awash in numbers" (Steen et al. 2001, 1). Although societal changes precipitated and justified much of this turn-of-the-century work, change is not necessarily wellaccounted for in numeracy scholarship, even with Cohen $(1999,5)$ stating that "numeracy now looms as the successor to literacy."

We wondered: How might numeracy theories respond to continuously changing social worlds? For some guidance, we turned to literacy scholars, where theorists have also dealt with the challenge of developing theories that reflect 
change. Leu et al. $(2013,1150)$, for instance, argued that literacy theories must grapple with the reality that literacy has become deictic:

This simple idea carries important implications for literacy theory, research, and instruction that our field must begin to address. Deixis is a term used by linguists to define words whose meanings change rapidly as their context changes...To be literate tomorrow will be defined by even newer technologies that have yet to appear and even newer discourses and social practices that will be created to meet future needs. Thus, when we speak of new literacies, we mean that literacy is not just new today; it becomes new every day of our lives.

Our specific focus in this article is on the six propositions of a social theory of literacy proposed by Barton and Hamilton (2000). With roots in ecological models of literacy, "the starting-point of this approach is the assertion that literacy is a social practice" (Barton and Hamilton 2000, 7, emphasis in original). This startingpoint implies many things about literacy and can be restated as an answer to the question 'what is literacy?' (Perry 2012). For social practice literacy theorists, that answer is "what people do with reading, writing, and texts in real world contexts and why they do it" (Perry 2012, 54).

Considering quantitative practices, Denning (1997) suggested that simple conceptions of numeracy might be inadequate for what our scholars cared about. Denning $(1997,106)$ argued that the "world of practices is messy: practices defy descriptions; new practices are constantly emerging; others becoming obsolete; practices evolve in harmony with technologies." That quantitative practices change implies that numeracy - conceptualized as social practices - also changes. Orrill (2001, xiii) highlighted this point: "literacy can have no permanent meaning, no definition forever fixed and constant across all times and places."

A social theory of numeracy can reflect the realities of change by incorporating change into the theory and purposefully resisting a fixed definition of numeracy. The social practices that make up numeracy, then, are continually open to scrutiny, replacement, and refinement. From a 'practices' starting-point, we present a social theory of numeracy by adapting and expanding six propositions (Barton and Hamilton 2000, 8):

Proposition \#1: Numeracy is best understood as a set of social practices; these can be inferred from events which are mediated by quantification.

Proposition \#2: There are different numeracies associated with different domains of life.

Proposition \#3: Numeracy practices are patterned by social institutions and power relationships, and some numeracies are more dominant, visible, and influential than others.

Proposition \#4: Numeracy practices are purposeful and embedded in broader social goals and cultural practices.

Proposition \#5: Numeracy is historically situated.

Proposition \#6: Numeracy practices change and new ones are frequently acquired through processes of informal learning and sense-making. 


\section{Proposition \#1: Numeracy is best understood as a set of social practices; these can be inferred from events which are mediated by quantification}

Numeracy cannot be abstracted from reality; it is neither mathematics nor abstract statistics and probability. The intimate tethering of numeracy to the social world is what distinguishes it (e.g., Steen et al. 2001). Whereas literacy is mediated by written text, numeracy involves quantification. We conceptualize quantification as socially produced, whereby people do mathematics and statistics in the process of comprehending their world. Size, shape, direction, magnitude, quantity, classification, projection, comparison-these are some examples of how quantification acts as a form of social construction, which Best $(2008,2)$ described as: "the processes by which people assign meaning to their world." Numeracy is a collection of forms and reasons of social activities - specifically the collection of how and why people act when they are interacting with quantification.

Some numeracy scholars have begun exploring the social construction of numbers in serious detail (e.g., Best 2008; Sauder and Espeland 2009; Andreas and Greenhill 2010; Himmelstein 2013, 2014). In our social theory of numeracy, however, quantification is not only social during its construction (in the sense that people do the quantifying), it is also social thereafter. People interact with it in any manner of ways. Following a sociological tradition, our interpretation of social is, as Best $(2008,2)$ stated, defined "very broadly, as encompassing of all the ways people interact."

Quantification, like written text, is produced for many potential reasons, including communication, argumentation, and sense-making. Our choice to replace Barton and Hamilton's literacy focus on written text with quantification has significant implications for numeracy scholarship. The concept of quantification can act as an anchoring idea when discussing the influence and limits of numeracy. Further, we believe the quantification best represents the numeracy analogue to text. How and why people produce quantification-and how and why people interact with the quantification thereafter-are social practices. These social practices exist "in the relations between people, within groups and communities, rather than as a set of properties residing in individuals" (Barton and Hamilton 2000 , 8). By introducing relationships to numeracy practices, we must confront important ideas including: power, trust, responsibility, and ethics_all ideas that complexify numeracy while also clarifying what is involved.

A potentially powerful implication of conceptualizing numeracy as a set of social practices is that it de-centers what people do not do (an inexhaustible list), and instead centers the exploration and explanation of what people do. A person might quantify their thinking, share or hide how they measure or what they chose to count; a person might present their quantification as opinion or fact, or ignore 
quantities that run counter to their beliefs. All of these actions "connect people with one another, and they include shared cognitions represented in ideologies and social identities" (Barton and Hamilton 2000, 8). There are reflexive relationships between what people do with quantification and why they do it, and histories, power, and purposes, which involve individual, social, and cultural dynamics.

Numeracy practices are what people do with quantification, but they "are not observable units of behavior since they involve values, attitudes, feelings, and social relationships" (Barton and Hamilton 2000, 7, citing Street 1993, 12). Numeracy scholars infer numeracy practices from observations of interactions between people and quantification: numeracy events. If literacy events are those "activities where literacy has a role" (Barton and Hamilton, 8), numeracy events (Baker and Street 1996; Baker 1998; Baker et al. 2003) are those activities where numeracy has a role because they are mediated in part by quantification. Numeracy events are observable, similar to written texts and literacy events. Whereas deciding what counts as a numeracy event is subjective, once decided, some of what people do during the event can be observed and recorded. That a person took out a second mortgage, or voiced a perspective on a new economic policy, or sold their car, or ignored particular quantitative risk data, or inquired about the absence of quantitative information - all these are observable numeracy events.

Street, Baker, and Tomlin (2006) produced an important ethnographic account of numeracy events in the home and in school. By identifying and analyzing critical incidents of numeracy events and practices in the home, as case studies, these scholars found that what people do during a numeracy event changes based on where the event occurs. Most notably, by recognizing numeracy events set in school as only one type of many, these scholars pressure us to think differently about the role of school mathematics and its relationship to numeracy practices people engage outside of school. They quite clearly demonstrated that there is not a single numeracy that can be abstracted from the social world and applied universally across different domains of life.

\section{Proposition \#2: There are different numeracies associated with different domains of life}

Numeracy can be considered plural-numeracies-because social practices are localized, in two ways. The first way numeracies are localized is identifiable by considering a single person: numeracies are localized in the sense that they are contextualized. The same person almost certainly does not engage the same social practices when engaged with quantification in all of their communities and environments. We do not act the same way in all domains of our lives, and numeracy theories should reflect that.

Steen et al. (2001) listed several spaces and domains where people might "express" numeracy (what we might consider spaces that are regularly mediated by 
quantification): citizenship, culture, education, professions, personal finance, personal health, management, and work. A social theory of numeracy implies that the people engage different numeracy practices in each of those domains because people have different relationships with different parts of their lives. A social theory of numeracy, therefore, rejects the notion of an overarching, singular "numeracy" that is globally applicable. Instead, since what people do when interacting with quantification in different spheres of their lives differs, we argue that our theories should reflect that complexity.

The concept of quantified risk is a useful example. The way the same person interacts with financial risk and medical risk is different, even if the mathematical and statistical pieces are abstractly the same. The numeracies involved therein are different because the context is different-loss of money is not the same as loss of health; financial planning is different than health maintenance. In their extensive psychometric study of risk perception and behavior, Weber, Blais, and Betz (2002, 282) concluded:

Our results strongly support the hypothesis that risk taking is domain-specific...risk attitudes inferred from behavior either directly or via utility functions that are derived from risky choices, are also domain-specific rather than reflections of a stable attitude or trait.

The authors argued that risk is not a stable attitude across domains because the same people account for the same calculations and utilities differently in each context. The domain-specificity of risk implies a domain-specificity of numeracy practices related to risk. That is, the same numbers, calculations, and comparisons literally mean different things to the same people in different contexts. We argue that parsing numeracy into multiple numeracies - into a set of social practices - is a defensible theoretical move (e.g., Oughton 2010).

The second way numeracies are localized is evident when considering two different people: numeracies are localized in the sense that they are personalized. What one person does during a particular numeracy event will not be the same as what a different person does. Further, two people might do the same things for different reasons. Both situations are indicative of the plurality of numeracy practices. Different communities will engage different social practices than each other, even when interacting with the same quantifications.

At this point, it is important for us to clarify a point which Best $(2008,2-3)$ discussed with social construction:

...when sociologists say that a statistic is socially constructed...they do not draw a distinction between socially constructed numbers and good numbers. Rather, they view all numbers as socially constructed; every number is a product of people's choices.

In a similar fashion, we are not drawing a distinction between numeracy practices and appropriate social practices with quantification. All social practices during events mediated by quantification are numeracy practices; what numeracies we 
might want to see are matters for discussion and debate. Numeracy practices are inferences that are open to debate, but the qualities and desirability of particular practices are also debatable. Whatever a numeracy scholar argues for the desirability of a numeracy practice, they also make inferences about why that practice occurs.

Gee $(1992,3)$ argued that "reading and writing only make sense when studied in the context of social and cultural (and we can add historical, political, and economic) practices of which they are but a part." The same can be said for mathematics and statistics when it comes to numeracy. Madison and colleagues (2009), for instance, compiled case studies of situated numeracy practice.

\section{Proposition \#3: Numeracy practices are patterned by social institutions and power relationships, and some numeracies are more dominant, visible, and influential than others}

Numeracy practices are not isolated. Why people interact in particular ways with quantifications they encounter (or create) is partially shaped by power. Quantification is purposeful and influenced by powerful institutions. For example, we grade people in school to separate them; we developed and use metrics for high school class rankings in order to make the process of college admittance more efficient; we take standardized tests graded into percentiles to comply with universities' efforts to decide who they should admit; we use a four-point system in university to comply with industry's efforts to decide who they should hire. Whether those quantifications are wholly effective or reasonable is debated, but there is no question that we make particular quantifications because of the influence of powerful institutions.

As quantifications are driven by these institutional powers, our numeracy practices when engaged with these quantifications are likewise influenced. We might try harder on particular assignments because they are worth more points, not because they are more exciting or important. We might take particular classes, such as Advanced Placement courses, because they are weighted more heavily in class ranking metrics, not because they reflect our interests or are better classes. We might retake the SATs in order to qualify for particular schools, not because doing better is meaningful to us. We might take university courses to maintain a high grade-point average, not because the courses are appropriate or meaningful for our futures. The numeracy practices we witness, and the reasons people do particular things during events mediated by quantification, is partially shaped by institutional forces.

As another example, take the uses of quantification in sports in the United States (e.g., Albert and Koning 2007). The sports entertainment industry produces a massive amount of quantification: from detailing what happened during specific games (i.e., basketball: points, rebounds, assists, turnovers, fouls, plus/minus ratio, 
etc.), to producing rarity statistics (i.e., the first team to accomplish something in so many years), to doing an immense amount of predictive modeling (i.e., chances of making the playoffs), to developing ranking metrics (i.e., the Top 25). Why produce all these numbers? Well, in-game statistics might provide a shorthand method for sharing what happened and comparing outcomes, and keeping people feeling like they did not miss the game so they can keep following their teams. Rarity statistics might provide some sense of wonder about the current event, and keep people interested. Predictive modeling brings future games into the present discussion, creating hype for next week's matchup. Ranking metrics create significant debate, but also structure attempts to create the most high-profile matchups (as in the College Football Playoffs). There are likely many more explanations for the mass production of quantification, but arguably, these numeracy practices are patterned by the entertainment industry; they are designed to increase and maintain interest in a product, in order to generate revenue.

The sports example helps illustrate how numeracy practices are influenced by social institutions. People who enjoy sports interact constantly with quantification. Many numeracy practices flow from this environment. Take rankings, for example: we might dismiss rankings as biased, thinking that preseason rankings are major (and perhaps undue) influences on postseason rankings. We might dismiss rankings as foolish, thinking that accurately comparing teams that do not play is not possible. We debate who is overrated and who is underrated. We discuss how the National Football League ranking system is better than the College Football ranking system, and much more. Debatable metrics are used authoritatively to make decisions. For instance, the top four ranked College Football teams make the College Football Playoffs. The numeracy practices that emerge are structured by the fact that sports entertainment produces and relies upon these quantifications. If the industry did not create these quantifications, there would be different, and likely fewer, numeracy events in sports.

Predictive modeling is not only highly visible in the sports domain, but also in environment, in politics, in economics, and in business. By studying numeracy from a social perspective, instead of studying how people can learn to better understand and interact with predictive modeling, we can ask: Why is predictive modeling so visible? Perhaps it is because people trust numbers to organize their future more than other means; that people, as Porter (1996) said, "trust in numbers" differently than other concepts. The contrast between numeracy education which prioritizes comprehending quantification with numeracy education that prioritizes questioning quantification could be significant.

Which numeracy practices are more visible is subject to debate. Arguably the most visible numeracy practices are those evident within school. That is, the practices which are emphasized when interacting with quantification as a part of school curricula. These include content themes like abstraction, simplification, 
procedure-following, as well as context themes like spending money, simplified business scenarios, highly simplified physical world scenarios, and the platonic realm. Their visibility is signified by the importance we give mathematics as a gatekeeper to livelihoods.

From the social perspective, the visibility of particular numeracy practices is important because it is fundamentally linked to the power and influence that social institutions exert on human activity. At the same time, numeracy practices are not fully driven by outside influence on individual behavior. The reciprocal relationship between institutions and individuals exists simultaneously, wherein individuals also practice numeracy based on personal preferences, and interact with quantification purposefully, even as those purposes interact with broader institutional goals.

\section{Proposition \#4: Numeracy practices are purposeful and embedded in broader social goals and cultural practices}

Numeracies are rationalizable. People can defend what they do when interacting around quantification. As reading and writing are only occasionally and narrowly done for their own ends, so too are mathematics and statistics. Literacy is always purposeful, and so too is numeracy. The broader social goals for literacy are mirrored in calls for numeracy as a goal-directed practice toward informed personal decision-making, or economic empowerment, or resolving public problems. Numeracy is embedded into larger social goals and cultural practices. The ability to precisely calculate interest payments reflects a cultural practice of taking on debt; the concern with patients' ability to accurately calculate dosage reflects a scientific practice in which medicine is regimented and ingested precisely; the concern over fair gerrymandering strategies reflects a particular voting scheme; and the debates over healthcare systems are inseparable from ethical discussions regarding shared humanity and community.

The concept of motivated numeracy, developed by Kahan et al. (2017), illustrates the rationalizability of the numeracy practices people choose to engage. Although the authors operationalize numeracy into a measurable, hierarchical concept of mathematical ability, they found that people engaged their mathematical ability differently depending on circumstance. In other words, people were motivated to use their mathematical ability in order to best suit their purposes; they found that people with higher mathematical ability "would use their quantitativereasoning capacity selectively to conform their interpretation of the data to the result most consistent with their political outlooks" (Kahan et al. 2017, 54). Mehta and Guzmán (2018), for instance, found examples of spatial manipulation with quantitative visual rhetoric from media outlets (across the political spectrum) during the 2016 U.S. presidential election. This manipulation involved both multimodal design choices and quantification that advanced particular storylines. 
Within this social theory of numeracy, we can rephrase these findings: numeracy is not mathematical ability, but instead, the social ways in which people engage that ability. Numeracy is therefore motivated by broader concerns for social goals, and mathematical ability is strategically employed because numeracies are purposeful.

The embeddedness of numeracy practices implies that numeracy practices occur at the same time as other social practices. Indeed, the absence of quantitative considerations can be understood as a numeracy practice of a person deciding that quantitative information is irrelevant to the argument and conclusion at hand. Although this decision can be debated (and often is, in our literature), that this decision is undertaken only by those who either do not know enough mathematics or do not appreciate the importance of their mathematics knowledge is only one possible inference about the numeracy event. Among the complexity of real-life decisions, and at their speed, reasoning quantitatively is an option that can reasonably be left out. Indeed, the complexity of human decision-making necessitates the omission of ways of thinking and reasoning in real time (Tunstall, Matz, and Craig 2018).

The implications of numeracy practices being purposeful can also reframe the idea of innumeracy. Take the concept of motivated innumeracy as an alternative inference about why people disregard or furiously disagree with the results of particular quantification. Numeracy scholars might argue that these choices simply reflect mathematical or statistical inabilities or under-appreciation. Wadsworth (1997, 12), however, illustrated an example of motivated innumeracy in her discussion of federal budget issues and numeracy:

Defining this issue in terms of public innumeracy feeds into a view that is all too common among the national leadership, and one that is deeply resented by the public. It suggests the public is stupid and the experts are smart, and if people were just a little less dumb or a little more mathematically sophisticated, we could balance the budget and solve more of our national problems... We see the root problem not as a conflict between an innumerate and uneducated public versus a numerate and sophisticated elite, but as a conflict between the public's moral and value-driven perspective on issues and an expert perspective that is increasingly technical and value-free.

Wadsworth's inference that our dismissal of quantification might sometimes be rooted in a perceived ideological incompatibility is a less dominant, visible, and influential inference than that of people being unable to do particular technical mathematical or statistical processes. Here we use "innumeracy" somewhat ironically in reference to the commonplace ability inferences made by scholars, as opposed to an inference that some people comprehend what they are doing when they choose to be "innumerate." When numeracy practices are viewed within larger ideological debate, the history of those debates exerts influence on what we might observe in current numeracy events. 


\section{Proposition \#5: Numeracy is historically situated}

Numeracy practices have a past. In some sense, numeracy is a fairly recent development, newly relevant after the proliferation of computers, when "as the printing press gave the power of letters to the masses, so the computer gives the power of numbers to ordinary citizens" (Steen 1997, xi). Some of the first uses of the English terms "numeracy" and "quantitative literacy" appear to be Crowther's 1959 policy report in London, England, and Douglass' 1942 essay regarding "the importance, in total war, of quantitative literacy in the citizen" (212). Neither term rose to any sort of common use until several decades later, in the 1980s and 1990s.

In another sense, the emergence of numeracy as a term reflects an evolution of longstanding narratives about the role of quantification in society (Porter 1996; Craig 2017). Some scholars have used the contemporary term 'numeracy' to discuss the past, as a lens to express the emerging uses of quantification in different aspects of society, most prominently in politics and economics. Cohen's (1999, 2001) historical accounts of numeracy in the United States during the $18^{\text {th }}$ and $19^{\text {th }}$ centuries highlighted much of the same skills and dispositions as some contemporary conceptions: an ability and willingness to interact with everyday arithmetic and statistics. Cohen argued that her "central topic was both a frame of mind and a concrete skill that was perfectly captured in the word numeracy" (1999, ix, italics in original).

A social theory of numeracy should involve attempts to trace the "ideology, culture and traditions on which current practices are based" (Barton and Hamilton $2000,13)$. In other words, numeracy practices are not simply reflections of newly modern demands, but have partially recognizable pasts. Nowhere is this better visible than in William Deringer's thesis on the evolution of the use of quantification in public policy discourse. Three-hundred years ago, British policymakers found themselves, in relation to quantification and public numeracy:

...in a kind of persistent political numbers game, in which it was more or less expected that political policies would be justified by recourse to calculations, and it was similarly expected that such justifications would be subjected to unforgiving computational scrutiny by opposing calculators. It was not a very good game by most standards. Competitors tried to set their own rules and so often found themselves playing by different ones. Contests were often very unsporting, and it was rarely clear who, if anyone, ever won. But political leaders and their opponents found it was a game they had to play, because it was too costly not to, because to cede the numerical ground was to give up far too much. (Deringer 2013, 393)

He argued that this political climate arose connected to emerging connections between quantification and objectivity. As quantification entered the public policy context in Britain, he found that people using quantification to argue public policy had to develop different abilities: 
These public calculators had to think very creatively about how to build coherent numerical arguments out of incomplete data, cleverly using estimations, interpolations, and proxy variables to fill in the information they so often wanted but could not get. At the same time, they had to think deeply about how to make their own arguments clear and credible to a broader audience, probably far less numerate than they were. Finally, such calculators also had to think about how their arguments would hold up under the scrutiny of partisan opponents, and, alternately, how they might use computations to pick apart and discredit those opponents' claims. All of these political-economic calculators were driven, sometimes entirely, by the demands of public and partisan politics, by the need to make effective arguments, not enduring theories or iconic texts. (Deringer 2013, 397, emphasis in original)

Deringer's sociological approach generated an historical account of the proliferation of quantification into public policy in Britain in the late $17^{\text {th }}$ and early $18^{\text {th }}$ centuries. His analysis provides a stunning example of the embeddedness of numeracies into broader social goals. The numeracies these public calculators engaged varied from other contexts because they were driven by why the quantification was occurring - to propose and defend public policy. More than that, he clearly demonstrated how the past has influenced the present, wherein quantification is an expected method of argumentation and counter-argumentation.

Numeracy scholars, among others, are currently debating the roles of quantification in public policy (e.g. Erickson 2017). We live in a highly quantified public environment, where quantification is nearly impossible to exclude from even moral public claims, and is increasingly relied upon in the age of big data. A social theory of numeracy challenges the idea that numeracy remains the same across contexts, as well as through time. Historical methods for studying numeracy within a social theory require an acknowledgement of how present ideas are grafted onto the past. A history of numeracy can only be retold from the present, and is only a historical telling of the present of numeracy (Craig 2017). Why are the dominant numeracy practices what they are? And, where might numeracy go in the future, as the world continues to change?

\section{Proposition \#6: Numeracy practices change and new ones are frequently acquired through processes of informal learning and sense-making}

Numeracy is dynamic. A reciprocal relationship between social practices and technology fosters an environment where new and transformed numeracy practices develop and some current practices fade. Technological changes like Twitter and other social (and digital) media platforms change the quantifications that mediate numeracy practices, and people create new practices within those media (Craig, Mehta, and Howard 2018). Numeracy, therefore, may be deictic-constantly changing and "ever more apparent and pressing (albeit in different ways to different groups)" (Steen et al. 2001, 19). 
These changes can happen at several different levels of relationships. For instance, groups (like governments and researchers) have valorized the concept of big data, as in movements for data-based decision making; individuals can also begin practicing numeracies in new ways, "across their lifetime, as a result of changing demands, available resources, as well as possibilities and their interests" (Barton and Hamilton 2000, 14). For example, even as big data emerges as technologically possible, scholars highlight the thinning of data as it is more readily generated at massive scales (e.g., Bollier and Firestone 2010).

The so-called Web 2.0 era of Internet communication also transformed numeracy practices by creating different, new numeracy events. People engage each other through the Internet on social media in significantly different ways, including increased anonymity and a many-to-many media relationship (Craig, Mehta, and Howard 2018). Technological changes also impact the classroom. For instance, Craig has used Gapminder (gapminder.org), a repository of worldwide data sets coupled with an interactive, free piece of software, to organize classrooms about data. By allowing users to see a two-variable scatterplot augmented with three additional dimensions (size, color, and a "play" button), Gapminder creates a different numeracy event than interacting with traditional scatterplots. With different numeracy events come different numeracy practices, such as expecting to think about relationships between variables over time or thinking about clusters of data moving within a larger scatterplot.

A dynamic framing of numeracy practices allows for recognition of the complexity of sense-making. In other words, numeracy practices and numeracy events are constantly in motion and new numeracy practices emerge because human beings are constantly making sense of the world in complex ways. This opens possibilities to center conversations on what people $d o$-with attention to power, purposes, histories, and more - rather than getting stuck in questionable deficit discourses that often perpetuate the same problems (Oughton 2018). We suggest that holding onto solely predefined numeracy practices on which students are judged in mathematics classrooms might not make much sense. A social theory of numeracy that normalizes change encourages space to allow for flexibility and complexity that is part of this sense-making.

\section{Discussion}

In this article we described a particular social theory of numeracy constructed from Barton and Hamilton's (2000) original social theory of literacy. We hope this article enters into our collective discussion of theorizing in numeracy. We see theorizing as an integral part to the maturation of our field, both in advancing our thinking and in disrupting our commonsense conceptualizations. Several scholars have already described the promise of social theories for numeracy (e.g., Street, Baker, and 
Tomlin 2006; Oughton 2010, 2018), so our contribution was simpler: a numeracy translation of Barton and Hamilton's specific social theory.

We want to continue to reflect upon and engage with the potential implications of the perspectives - both implicit and explicit - in our work. What inferences might (and do) we choose to make, and how are these inferences shaped by (and simultaneously reshape) power, purposes, and histories? Inferences about 'low' numeracy cannot be separated from historical narratives about mathematics ability, mathematics education, and educational reform, for instance (Craig 2017). Additionally, as mathematics educators, we are concerned with the feasibility of schooling under this theoretical perspective.

In this way, we confront an educational problem that Coben (2006) has called the "atomization" of numeracy - that the vast number of ways that quantification enters into different domains of life is incompatible with curriculum design. This social conception of numeracy does pose a significant challenge to traditionally organized curricula. If numeracy is situated in context, then the choice of context becomes incredibly important and is the central topic of curriculum design. Craig (2017) argued that we should build our curricula from a strong premise: that nothing learned within the course could be applied to different contexts, but only to what was directly explored in the course. This premise created an ethical imperative to deeply discuss what contexts deserved our educational time and energy, and which should be excluded in specific co-designed courses on numeracy. Our approach to solving this problem was to identify module topics based on three criteria: importance, usefulness, and interest. We initially settled on modules in politics, economics, media, health and risk, demographics, and natural science, and in different instantiations of the courses have also run modules around law and justice.

We also addressed the premise in a second way, out of a knowledge that all of our students would not find all of our modules important, useful, and interesting. That is, the criteria for choosing a module were satisfied only from the perspective of our design team, although we did try to hypothesize whether students would agree. Part of the expected improvement process was piloting and revising the courses, and improving the modules. However, we wound up also designing course-long projects where students could choose their own contexts, and investigate the overlaps and differences between their work and our course work. This was an unexpected curricular development that grew out of feedback and curriculum revision attempts (Craig 2017).

Within both the course work and project work, students pursued different lines of thinking, applied and critiqued quantification in different ways, and ultimately demonstrated the importance of situated knowledge for understanding quantification. Further, students sometimes succeeded in understanding and producing quantification on their projects that they did not do successfully in other contexts. This problematizes the second critique of social theories of numeracy that 
Coben $(2006,108)$ identified, which implies that mathematics proficiency comes before numerate use of mathematics.

Why did students involved in different numeracy events act and react to the quantification in the ways that they did? Perhaps students differently succeeded in doing particular mathematical and statistical work because their knowledge of the context clarified the quantitative aspects or gave them better insight to their meanings. Indeed, Craig (2017) found that students chose not to do particular quantitative techniques, even though they were able to perform them. For instance, students leveraged their personal knowledge about the measurability of happiness - its fluidity, variety, and multiplicities - to argue that quantifying happiness was impossible. This argument reframed their reluctance to understand large-scale efforts to measure and affect happiness (Craig 2017).

In fact, some students were not only skeptical of these efforts to measure happiness, but opposed them. By explicitly acknowledging the presence and influence of histories, power, and purposes - both during a numeracy event and in our scholarship - we argue that a social theory of numeracy offers something different to scholars who study and discuss numeracy. And through those differences, we believe a social theory of numeracy can help diversify our scholarship. The primary differences we want to highlight are: (1) a social theory supports an intentional focus on what people do ("numeracies"), as opposed to what people do not do ("innumeracies"); (2) a social theory acknowledges the social realities of power and history and supports scholarship that is more explicit about those realities; (3) a social theory unfreezes what numeracy means and, therefore, supports an open dialogue not needing to be settled in order to be better studied; and (4) a social theory of numeracy is more readily connected to theories of other forms of thinking and reasoning, including: literacy, social science, art, digital literacy, scientific literacy, logic, intuition, philosophy, ethics, and others.

In no way do we posit that this social theory of numeracy is correct nor finished. As a contribution to the scholarly dialogue, we illustrated how we thought about and translated a social theory of literacy into our own work on numeracy. We hope that this account can encourage others to either use our numeracy translation of Barton and Hamilton's theory of literacy, or consider the usefulness of other approaches to numeracy scholarship. We believe there is ample opportunity to understand numeracy in new ways by exploring theoretical alternatives.

For our personal work, we have already used social theories to develop and study two newly developed undergraduate courses in numeracy (Tunstall et al. 2016; Craig 2017; Craig 2018; Craig, Guzmán, and Krause 2018; Craig, Guzmán, and Harper 2018; Craig, Mehta, and Howard 2018). Moving forward, we intend to pursue implications for numeracy of not only the social turn, but also the cultural and political turns. These works include deconstructing the concept of numeracy and its discourse to question the viability of our goals for numeracy, such as the 
concept of the quantitative reasoner. Finally, we hope to explore the potential for numeracy as a transdisciplinary adjustment of mathematics and statistics for education organized not around disciplines, but rather around problems (Craig 2017; Craig, Guzmán, and Krause 2018)

\section{References}

Albert, J., and R. H. Koning. 2007. Statistical Thinking in Sports. Boca Raton, FL: CRC Press. https://doi.org/10.1201/9781584888697.

Andreas, P., and K. M. Greenhill. 2010. Sex, Drugs, and Body Counts: The Politics of Numbers in Global Crime and Conflict. Ithaca, NY: Cornell University Press.

Baker, D. 1998. "Numeracy as Social Practice." Literacy and Numeracy Studies 8 (1): 37-50.

Baker, D., and B. Street. 1996. "Literacy and Numeracy Models." In The International Encyclopedia of Adult Education and Training, ed. A. C. Tuijnman, 79-85. New York, NY: Elsevier Science.

Baker, D., B. Street, and A. Tomlin. 2003. "Mathematics as Social: Understanding Relationships between Home and School Numeracy Practices." For the Learning of Mathematics 23 (3): 11-15. http://www.jstor.org/stable/40248426 (accessed October 19, 2017).

Barton, D., and M. Hamilton. 2000. "Literacy Practices." In Situated Literacies: Reading and Writing in Context, ed. D. Barton, M. Hamilton, and R. Ivanic, 7-15. New York, NY: Routledge.

Bass, H. 2003. "What Have We Learned. . . and Have Yet to Learn?" In Quantitative Literacy: Why Numeracy Matters for Schools and Colleges, ed. B. Madison and L. A. Steen, 247-249. Princeton, NJ: The National Council on Education and the Disciplines.

Best, J. 2008. "Birds_-Dead and Deadly: Why Numeracy Needs to Address Social Construction." Numeracy 1(1): Article 6. https://doi.org/10.5038/1936-4660.1.1.6 (accessed October 19, 2017).

Bollier, D., and C. M. Firestone. 2010. The Promise and Peril of Big Data. Washington, D.C.: Aspen Institute, Communications and Society Program.

Coben, D. 2006. "The Social-Cultural Approach to Adult Numeracy: Issues for Policy and Practice.” In: Tett, L.; Hamilton, M.; Hillier, Y., eds. Adult Literacy, Numeracy and Language: Policy, Practice and Research. Columbus, OH: Open Universities Press/McGraw-Hill.

Cohen, P. C. 1999. A Calculating People: The Spread Of Numeracy In Early America. New York, NY: Psychology Press. 
Cohen, P. C. 2001. "The Emergence of Numeracy." In Mathematics and Democracy: The Case for Quantitative Literacy, ed. L. A. Steen, 23-30. Princeton, NJ: The National Council on Education and the Disciplines.

Craig, J. C. 2017. Real Fantasies in Mathematics Education: Numeracy, Quantitative Reasoners, and Transdisciplinary Wicked Problems. Ph.D. dissertation, Michigan State University.

Craig, J. C. 2018. "The Promises of Numeracy: Pressure on Mathematics Education to Reform." Working paper, University of Arizona. Revised and resubmitted and under review.

Craig, J. C, L. D. Guzmán, and F. K. Harper. 2018. "Quantitative Literacy Scholarship from Individualist, Collectivist, and Activist Perspectives." Working paper, Michigan State University. Submitted and under review. Craig, J. C, L. D. Guzmán, and A. Krause. 2018. "The Potential Virtues of Wicked Problems for Education." Paper presented at the 21st Annual Meeting of the Conference on Research in Undergraduate Mathematics Education, San Diego, CA. http://sigmaa.maa.org/rume/crume2018/Abstracts_Files/Submissions/140_Th e_Potential_Virtues_of_Wicked_Problems_for_Education.pdf (accessed April 16, 2018).

Craig, J. C, R. Mehta, and J. Howard. 2018. "Quantitative Literacy to Quantitative Literacies: Effects of Social Media.” Working paper, Michigan State University and University of Maryland University College. Submitted and under review.

Crowther, G. 1959. 15 to 18: A Report of the Central Advisory Council for Education (England). London: Her Majesty's Stationery Office.

Davis, B. 2008. "Complexity and Education: Vital Simultaneities." Educational Philosophy and Theory 40 (1): 50-65. https://doi.org/10.1111/j.14695812.2007.00402.x (accessed October 19, 2017).

Denning, P. J. 1997. “Quantitative Practices.” In Why Numbers Count: Quantitative Literacy for Tomorrow's America, ed. L. A. Steen, 106-117. New York, NY: College Entrance Examination Board.

Deringer, W. P. 2012. Calculated Values: The Politics and Epistemology of Economic Numbers [n Britain, 1688-1738. Ph.D. Dissertation, Princeton University. http://arks.princeton.edu/ark:/88435/dsp01xk81jk423 (accessed April 16, 2018).

Douglass, H. R. 1942. "Mathematics for All.” The Mathematics Teacher, 35(5), 212-216.

Erickson, A. W. 2016. "Rethinking the Numerate Citizen: Quantitative Literacy and Public Issues." Numeracy 9 (2): Article 4. https://doi.org/10.5038/19364660.9.2.4 (accessed October 19, 2017). 
Erickson, A. W. 2017. "Rethinking the Numerate Citizen: Quantitative Literacy and Public Issues-Reply." Numeracy 10 (2): Article 13. https://doi.org/10.5038/1936-4660.10.2.13 (accessed December 3, 2017).

Gee, J. P. 1992. The Social Mind: Language, Ideology, and Social Practice. New York, NY: Bergin \& Garvey.

Gee, J. P. 2010. "A Situated-Sociocultural Approach to Literacy and Technology." In The New Literacies: Multiple Perspectives on Research and Practice, ed. E. Baker, 165-193. New York, NY: The Guilford Press.

Gutiérrez, R. 2013. "The Sociopolitical Turn in Mathematics Education." Journal for Research in Mathematics Education 44(1): 37-68. https://doi.org/10.5951/jresematheduc.44.1.0037 (accessed October 19, 2017).

Hamman, K. H. 2017. "Rethinking the Numerate Citizen: Quantitative Literacy and Public Issues-Discussion." Numeracy 10(2): Article 12. https://doi.org/10.5038/1936-4660.10.2.12 (accessed December 3, 2017).

Himmelstein, J. L. 2013. "Hidden Choices and Missing Numbers: Selecting Drug Numbers for Media Attention." Journal of Drug Issues 43(4): 437-449.

Himmelstein, J. L. 2014. "How the Mass Media Use Numbers to Tell a Story: The Case of the Crack Scare of 1986." Numeracy 7(1): Article 2. https://doi.org/10.5038/1936-4660.7.1.2 (accessed December 3, 2017).

Kahan, D. M., E. Peters, E. C. Dawson, and P. Slovic. 2017. "Motivated Numeracy and Enlightened Self-Government." Behavioural Public Policy 1(1): 54-86.

Karaali, G., E. H. Villafane Hernandez, and J. A. Taylor. 2016. "What's in a Name? A Critical Review of Definitions of Quantitative Literacy, Numeracy, and Quantitative Reasoning." Numeracy, 9(1), Article 2. https://doi.org/10.5038/1936-4660.9.1.2 (accessed March 19, 2018).

Lave, J. 1988. Cognition in Practice: Mind, Mathematics and Culture in Everyday Life. Cambridge, MA: Cambridge University Press. https://doi.org/10.1017/CBO9780511609268.

Lerman, S. 2000. "The Social Turn in Mathematics Education Research." In Multiple Perspectives on Mathematics Teaching and Learning, ed. J. Boaler, 19-44. London: Ablex.

Leu, D. J., C. K. Kinzer, J. Coiro, J. Castek, and L. A. Henry. 2013. “New Literacies: A Dual-Level Theory of the Changing Nature of Literacy, Instruction, and Assessment." In Theoretical Models and Processes of Reading, ed. D. Alvermann, N. Unrau, and R. Ruddell, 1150-1181. Newark, DE: International Reading Association. https://doi.org/10.1598/0710.42.

Madison, B. L., S. Boersma, C. L. Diefenderfer, and S. W. Dingman. 2009. Case Studies for Quantitative Reasoning: A Casebook of Media Articles, 2nd ed. New York, NY: Pearson. 
Mehta, R. and L. D. Guzmán. 2018. "Fake or Visual Trickery? Understanding the Quantitative Visual Rhetoric in the News." Working paper, University of Iowa and University of Arizona. Submitted and under review.

Orrill, R. 2001. "Mathematics, Numeracy, and Democracy." In Mathematics and Democracy: The Case for Quantitative Literacy, ed. L. A. Steen, xiii-xx. Princeton, NJ: The National Council on Education and the Disciplines.

Oughton, H. M. 2010. “We All Play Teacher”: A Study of Student Discourse in Adult Numeracy Classrooms. Ed.D. thesis, University of Sheffield. http://etheses.whiterose.ac.uk/15114/ (accessed April 16, 2018).

Oughton, H. M. 2018. "Disrupting Dominant Discourses: A (Re)Introduction to Social Practice Theories of Adult Numeracy. Numeracy 11(1): Article 2. https://doi.org/10.5038/1936-4660.11.1.2 (accessed January 30, 2018).

Papen, U. 2005. Adult Literacy as Social Practice: More than Skills (New Approaches to Adult Language, Literacy and Numeracy). Oxford: Routledge. https://doi.org/10.4324/9780203347119.

Paulos, J. A. 1988. Innumeracy: Mathematical Illiteracy and Its Consequences. New York, NY: Macmillan.

Perry, K. H. 2012. "What is Literacy? - A Critical Overview of Sociocultural Perspectives." Journal of Language and Literacy Education 8(1): 50-71. http://jolle.coe.uga.edu/wp-content/uploads/2012/06/What-isLiteracy_KPerry.pdf (accessed October 19, 2017).

Porter, T. M. 1996. Trust in Numbers: The Pursuit of Objectivity in Science and Public Life. Princeton University Press. https://doi.org/10.1515/9781400821617.

Sauder, M., and W. N. Espeland. 2009. "The Discipline of Rankings: Tight Coupling and Organizational Change." American Sociological Review 74: 63-82

Steen, L. A. 1997. Why Numbers Count: Quantitative Literacy for Tomorrow's America. New York, NY: College Entrance Examination Board.

Steen, L. A. 2001. "Mathematics and Numeracy: Two Literacies, One Language." The Mathematics Educator 6(1): 10-16.

Steen, L. A. 2003. "Reflections on Wingspread Workshop." In Calculation vs. Context: Quantitative Literacy and Its Implications for Teacher Education, ed. B. L. Madison and L.A. Steen, 11-23. https://www.maa.org/external_archive/QL/cvc/CalcVsContext.pdf (accessed October 19, 2017).

Steen, L. A., G. Burrill, S. Ganter, D. L. Goroff, F. P. Greenleaf, N. W. Grubb, J. Johnson, S. M. Malcom, V. Meeks, J. Moran, A. Packer, J. P. Ray, C. J. Shroll, E. A. Silver, J. Utts, and D. Wallace. 2001. "The Case for Quantitative Literacy." In Mathematics and Democracy: The Case for 
Quantitative Literacy, ed. L. A. Steen, 1-22. Princeton, NJ: The National Council on Education and the Disciplines.

Street, B. 1984. Literacy in Theory and Practice. Cambridge, MA: Cambridge University Press.

Street, B., D. Baker, and A. Tomlin. 2005. Navigating Numeracies: Home/School Numeracy Practices, Dordrecht: Springer. https://doi.org/10.1007/1-40203677-9.

Tunstall, S. L., R. L. Matz, Craig, J. C. 2018. "Quantitative Literacy Courses as a Space for Fusing Literacies.” Journal of General Education. 65(3-4): 178-194.

Tunstall, S. L., V. Melfi, J. Craig, R. Edwards, A. Krause, B. Wassink, and V. Piercey. 2016. "Quantitative Literacy at Michigan State University, 3: Designing General Education Mathematics Courses." Numeracy. 9(2):

Article 6. https://doi.org/10.5038/1936-4660.9.2.6 (accessed April 16, 2018). Vacher, H. L. 2014. "Looking at the Multiple Meanings of Numeracy, Quantitative Literacy, and Quantitative Reasoning." Numeracy. 7(2): Article 1. https://doi.org/10.5038/1936-4660.7.2.1 (accessed October 19, 2017).

Wadsworth, D. (1997). "Civic Numeracy: Does the Public Care?" In Why Numbers Count: Quantitative Literacy for Tomorrow's America, ed. L. A. Steen, 11-22. New York, NY: College Entrance Examination Board. Weber, E. U., A.R. Blais, and N. E. Betz. 2002. "A Domain- Specific RiskAttitude Scale: Measuring Risk Perceptions and Risk Behaviors." Journal of Behavioral Decision Making 15 (4): 263-290. 